\title{
Eyelid Muscle
}

National Cancer Institute

\section{Source}

National Cancer Institute. Eyelid Muscle. NCI Thesaurus. Code C52803.

The muscle in the orbit of the eye that lifts the upper eyelid. 